Sciendo

\title{
Blame and the Metaphysics of Practical Reasons
}

Elizabeth A. Oljar

University of Detroit Mercy

Disputatio No. 8

November 2002

DOI: $10.2478 /$ disp-2002-0009

ISSN: 0873-626X 
Disputatio 13, November 2002

\title{
BLAME AND THE METAPHYSICS OF PRACTICAL REASONS
}

\author{
Elizabeth A. Oljar \\ University of Detroit Mercy
}

\section{INTRODUCTION}

The degree to which moral theories or theoretical accounts of moral concepts cohere with various aspects of common sense moral thinking is typically regarded as an important criterion in assessing the adequacy of such accounts. First-order or normative ethical theories which implied that the Holocaust or slavery were morally permissible events would be rejected in virtue of their failure to cohere with considered or core moral beliefs; the ways we appeal to these events when teaching students about the implications of cultural relativism is perhaps the clearest illustration of this. Similar appeals are common in meta-ethics as well, although here we typically look at more general features of moral reasoning and discourse, as opposed to specific first-order moral judgments, in order to assess coherence. Thus, one common objection to Stevenson's classical version of non-cognitivism turns on common sense claims about moral disagreement and moral argument.

To my mind, therefore, it is a peculiar feature of much of the literature on internalism and externalism about practical reasons or justification that coherence with common sense morality is not often appealed to in the arguments given by proponents of either view. Instead, it is more common to find arguments for both views that rely on the conceptual connections between internalism or externalism and some other meta-ethical claim; for example, the connection between internalism and externalism on the one hand, and moral realism and anti-realism on the other. Although David Brink's work on internalism and externalism is perhaps the clearest example of this, it can also be seen in Stephen Darwall's argument that externalist accounts of reasons should be rejected in virtue of their conceptual commitment to an implausible Moorean nonnaturalist metaphysics (Brink 1986, 
1989; Darwall 1983). Such arguments are very different from appeals to common sense moral thinking in the sense that understanding them presupposes a considerable background in analytic moral philosophy itself, in a way that our appeals to slavery and the Holocaust when teaching relativism do not (if they did, discussions of these events would not be as pedagogically valuable as teachers of introductory ethics know them to be).

It should go without saying that whether one's account of reasons is consistent with one's other meta-ethical commitments is an extremely important subject for philosophical exploration; the work of philosophers such as Darwall and Brink is essential for developing a consistent overall meta-ethical view, and for demonstrating connections between various views that we might have overlooked. Such inquiries are the "meat-andpotatoes" of analytic meta-ethics, and of course, they also represent "good clean intellectual fun" for those of us drawn to this area of philosophy. But the very complexity of such inquiry, and the amount of intellectual energy required to undertake it seriously, make it easier to overlook the fact that reflection on ordinary or everyday moral practices, access to which requires no special philosophical training, may be just as illuminating as any complex meta-ethical argument. What is needed to improve our understanding of these issues is not "...the advancement and defense of complex theories" but rather "... a careful and honest consideration of cases" (Haines 1986, 64) ${ }^{1}$

For this reason, Bernard Williams' 1995 paper "Internal Reasons and the Obscurity of Blame" represents a distinctive contribution to the internalism literature. ${ }^{2}$ Williams claims that reflection on the moral practice of blame initially suggests a problem for an internalist account of reasons. He then argues that despite this initial appearance, the practice of blame is not a problem for the internalist; moreover, he argues that it is the externalist who cannot provide a satisfactory account of the practice of blame. In this paper, I show that both of these arguments fail. I begin by explaining Williams' conceptions of internalism and externalism (section 2), and I then critique

\footnotetext{
${ }^{1}$ Haines 1986 is an especially illuminating example of what reflection on specific cases and practices can reveal about our account of reasons.

${ }^{2}$ Williams has written two papers on internalist vs. externalist accounts of reasons: Williams 1981 and 1995. The later paper was intended to clarify the earlier paper, which relied almost entirely on the explanatory dimension of reasons to support an internalist account. He says of the earlier paper that "...there is something about this view, or the ways I have so far found to express it, that easily leads to misunderstanding" (Williams 1995, 35). This explains the different argumentative strategy employed in the later paper: reflection on a particular moral practice (such as blame) may help resolve the misunderstandings. In setting out Williams' account of reasons, however, it will be helpful to use the resources of both papers.
} 
Elizabeth A. Oljar

his arguments for both of the claims above (sections 3 and 4). Although I will grant much of what Williams says about the practice of blame itself, I will argue that an externalist account of reasons provides a more satisfactory explanation of this practice than an internalist account. Thus, while Williams has done us the great philosophical service of reminding us of the importance of reflecting on particular cases and practices in meta-ethical inquiry, I will argue that reflection on the practice of blame invites us to draw a very different set of conclusions about reasons.

\section{WILLIAMS' VERSION OF INTERNALISM}

Williams' conception of internalism and externalism centers on the truthconditions of statements that ascribe reasons to an agent, such as "A has reason to $\varphi$ " or "There is reason for A to $\varphi$. ." Internalism is the view that A's ability to reach a decision to $\varphi$ by a sound deliberative route from those motives A already has is a necessary condition of its being true that A has a reason to $\varphi$. We may express the same point by noting that an internal interpretation of the reason-statement implies that $\mathrm{A}$ has a motive that will be served by her ping, and thus the absence of the motive falsifies the reason-statement. The externalist denies that this is a necessary condition, so that "A has a reason to $\varphi$ " is not falsified by A's lacking a motive that would be served by her ping. Williams' discussion of both motives and 'sound deliberative routes' require further elaboration.

Williams uses the concept of an agent's "subjective motivational set" or $\mathrm{S}$, to expand our ordinary concept of a motive as a desire or preference (Williams 1981, 102). He stipulates that we can use the term 'desire' to formally refer to any element of an agent's $\mathrm{S}$, although he is clear that an agent's S includes her "dispositions of evaluation, patterns of emotional reaction, personal loyalties, and various projects...embodying the commitments of the agent" (Williams 1981, 105). Thus, my admiration of people who are honest, my tendency to cry at sad movies, and my desire to teach feminist political theory are all elements of my $\mathrm{S}$ in this sense. Of course, my $\mathrm{S}$ also includes desires in the more ordinary sense of that term, such as my desire for something to drink when I'm thirsty, or my specific desire for Mexican food to satisfy my hunger.

Williams is explicit in claiming that an agent's $\mathrm{S}$ is not a constant unchanging set of desires, for practical reasoning can itself alter the contents of one's $\mathrm{S}$ in a variety of ways (Williams 1981, 105). This fact raises the question of what Williams means by a "sound deliberative route" in his definition of internalism. Certainly a paradigm case of practical reasoning is 
the kind of instrumental rationality employed when we infer that we have a reason to $\varphi$ because ping represents the most efficient (or pleasant, or economical) way of satisfying an element in one's S. However, Williams denies that rationality is only instrumental; practical reasoning "does not merely involve perceiving means to an end that has already been formulated" (Williams 1995, 38). The inference that I have reason to watch a movie on videotape while eating dinner, because this would simultaneously satisfy two elements of my $\mathrm{S}$, is also an instance of sound practical reasoning. The same inference might reflect prior practical analysis of what constitutes a relaxing evening at the end of a hard day. Another example of sound practical deliberation would be my inferring that I have reason to teach a course in meta-ethics next semester, rather than a course on contemporary epistemology. The relative weights I attach to these elements of my $\mathrm{S}$, and the recognition that the circumstances are such that I cannot satisfy both, can generate this sort of reason-statement. In addition, imagination makes a substantial contribution to my practical deliberations in a variety of ways, such as my ability to envision alternative courses of conduct and their relation to elements of my S. For instance, instead of seeing my teaching choices as limited to either a course in meta-ethics or a course in contemporary epistemology, I might teach a course in moral epistemology. In moral contexts, the role of imagination is even more important, since the stakes are typically higher than in non-moral contexts. If a friend has cheated on her spouse, I may initially see only two courses of action for myself: tell the spouse or don't tell the spouse. Imaginative reflection, however, may reveal a third alternative, such as trying to persuade the cheating spouse to confess on her own. Which of these alternatives is chosen can have serious consequences for the moral relationships of everyone involved, and thus practical reasoning in this context would also involve reflection on ways of preserving those relationships, or deciding whether they should be preserved at all. The inferences drawn in these examples would all satisfy Williams' conception of a "sound deliberative route" (Williams 1981, 104; Williams 1995, 38). Williams is perfectly aware of the vagueness in his accounts of both the elements of an agent's $S$ and sound practical deliberation. However, he regards this as a virtue of his view, since the practical fact of the matter is that it "is often vague what one has reason to do" (Williams 1995, 38). Thus, the murkiness of Williams' view here simply mirrors a genuine vagueness in practical reasoning itself. ${ }^{3}$

This brief discussion of an agent's $S$ and of sound paths of practical reasoning illuminate Williams' definitions of internalism and externalism as

\footnotetext{
${ }^{3}$ For criticisms of Williams on these points, see Cohon 1986 and Hooker 1987.
} 
Elizabeth A. Oljar

different claims regarding the truth-conditions of reason-statements. Internalists and externalists do not (or at least need not) disagree about whether an agent's reasons must rationally support her actions, or whether its true that if $\mathrm{A}$ has reason to $\varphi$, then she can arrive at a decision to $\varphi$ by some rational process. Hence, the difference between internalists and externalists, according to Williams, turns on the status of the claim that A's ability to reach a decision to $\varphi$ by deliberative paths that begin at A's existing motivations is a necessary condition of its being true that A has reason to $\varphi$ : internalists regard this claim as true, while externalists regard it as false. ${ }^{4}$ With these views in mind, we can consider Williams' arguments about the connection between blame and reasons for action.

\section{IS BLAME A PROBLEM FOR INTERNALISM?}

Williams begins by specifying the sense of blame with which is he concerned, a notion he calls "focussed blame." Focussed blame has an explanatory dimension, but it is not the sort of causal explanation that we appeal to when we blame the dead battery for the car's failure to start in the morning. The explanatory element of focussed blame is distinctively normative; we blame agents for doing or failing to do certain things, and we typically posit various negative normative characteristics by way of explanation: the agent is selfish, nasty, inconsiderate, or something similar, and it

\footnotetext{
${ }^{4}$ It is important to point out that Williams' view of internalism and externalism does not adequately capture the number of views in the literature that have gone by these names. Darwall regards himself as an internalist, but argues against a view that is very similar to Williams'. According to Williams' versions of these views, Darwall would be an externalist, since he denies that the motives on which the existence of reasons depends are limited to those that the agent has prior to deliberation. Darwall claims that the relevant motives are often produced by sound deliberation, and thus need not exist prior to it. The complexity of the internalist literature requires a distinction between Humean and Kantian internalists. Humean internalists such as Williams are inspired by Hume's skepticism about reason's ability to produce motives ex nihilo, as it were, while Kantian internalists such as Darwall have greater faith in reason's ability to generate new motives by the process of rational deliberation itself. Thus, Williams and Darwall agree that there is a conceptual connection between an agent's reasons and her motives. They disagree about what I call "the priority thesis:" the motives on which the existence of reasons depends are those the agent has temporally prior to engaging in rational deliberation. Humean internalists accept the priority thesis, while Kantian internalists deny it. For Darwall's version of internalism, see Darwall, especially Chapter 2. For further discussion of the similarities and differences between Williams and Darwall, see Cohon 1993.
} 
is these characteristics that both explain the moral failure and ground our critique of it. Williams claims that some "generally reprehensible characteristic" of this kind must be part of the explanation in order for blame to be appropriate (Williams 1995, 40).

Why might the application of focussed blame cause a problem for internalism? Williams says that focussed blame "operates in the mode of 'ought to have'," and this modal operator tends to be connected with reasons for action. If it is appropriate to blame a person after an act (or a failure to act), then advising her prior to action that she ought to act (or ought not) is also appropriate. The force of 'you ought to have done $\varphi$ ' when blaming depends on the appropriateness of 'you ought to $\varphi$ ' when advising. In both cases, the term 'ought' is reasonably assumed to imply the presence of a reason. This point can be clarified, and its implications for internalism made more vivid, by considering a specific case Williams appeals to throughout his paper. He asks us to imagine a husband whose $\mathrm{S}$ lacks any element that would make it true that the husband has reason to be (or ought to be) kind to his wife. Telling this man that his wife's status as his spouse gives him a reason to be nicer to her has no effect; his response, we are to imagine, is "I don't care." No matter what we say, his response is the same. We might be tempted to blame the man, by saying both to and of him that he ought to be nicer to his wife, or that he had or has a reason to be nicer to her. His failure to do so both explains and justifies our labeling him as selfish or inconsiderate. If we are inclined to say to him that he ought to have acted otherwise, then presumably we would have been inclined to advise him to act differently in the first place.

A case of this kind causes a potential problem for the internalist because we are assuming that the man has no relevant element in his $\mathrm{S}$ that would give him an internal reason to be nicer to his wife. He has no motive from which he could, by a sound deliberative route, reach the conclusion to be nicer to his wife, and so by Williams' lights, it's false that he has an internal reason to be nicer to her. So if 'ought to have' suggests a reason for action, then whatever reason we think the man had must be an external reason. But if, as Williams claims, there are no external reasons for action, how are we to understand blame?

Williams' strategy in solving this problem is to acknowledge that blaming this man for failing to be nice to his wife is inappropriate, because he really has no reason to be nice to her. He then argues that this is not a troublesome result, partly because of the rarity of such cases, but more importantly because our inability to blame by ascribing a reason (or making the relevant 'ought' claim) in these cases does not exhaust our moral resources or leave us with no way to criticize his behavior. 
Elizabeth A. Oljar

The first step in Williams' argument is his claim that "I suspect that what are taken for external reason statements are often, in fact, optimistic internal reason statements: we launch them and hope that somewhere in the agent is some motivation that by some deliberative route might issue in the action we seek" (Williams 1995, 40). This suggests the explanation that Williams proposes for most cases of focussed blame: in many (if not most) of the cases where we think the agent has an external reason, what he really has is what we might call a "deep" internal reason. This is true because, as Williams rightly points out, "...blame is, much of the time, applied to people who do have some appropriate item in their S" (Williams 1995, 41). The person who has such an item may not be aware of this, or may not be aware of its bearing on the situation at hand. In such cases, a blaming expression such as 'you ought to have done $\phi$ ' will function as a "proleptic mechanism," as Williams calls it (Williams 1995, 42). Thus, "[t]o blame someone in this way is, roughly, to tell him he had a reason to act otherwise, and in a direct sense this may not have been true. Yet in a way it has now become true..." (Williams 1995, 41-42). Focussed blame thus "involves treating the person who is blamed like someone who had a reason to do the right thing but did not do it" (Williams 1995, 42).

The hard case of the man who is not nice to his wife must be handled differently, however, for he is clearly not like most people: his S really is lacking an appropriate element that might be reached by such a "proleptic mechanism." Williams says exactly what we would expect about this case: the man really does not have a reason, and blaming him is inappropriate. We cannot intelligibly say that he ought to have been nicer to his wife, or that he had a reason to do so. Williams says that "...it is precisely people who are regarded as lacking any general disposition to respect the reactions of others that we cease to blame, and regard as hopeless or dangerous characters rather than thinking that blame is appropriate to them. This represents the absence from their $\mathrm{S}$ of anything that can be reached by these mechanisms, anything it might even be hoped could yield recognition" (Williams 1995, 43).

It's clear that cases of this kind are very rare, and this is one reason why our inability to blame the man who is not nice to his wife shouldn't be disturbing. But even more importantly, according to Williams, is that this inability doesn't leave us completely bereft of moral criticism, for there are many moral judgments we can still make. Williams says that " $[\mathrm{t}]$ here are many things I can say about or to this man: that he is ungrateful, inconsiderate, hard, sexist, nasty, selfish, brutal, and many other disadvantageous things" (Williams 1995, 39). We can also say that "...his behaviour does not accord with what we think it should be" and "that it would be better if he 
acted otherwise" (Williams 1995, 40). ${ }^{5}$ Williams thinks that the fact that we can say all of these things is quite enough, and that there is no clear need for ascribing a reason to the man. Of course, that is precisely what the externalist wants to do here, and so what Williams wants to know is "... what is supposed to make it appropriate, as opposed to (or in addition to) all those other things that may be said? The question is: what is the difference supposed to be between saying that the agent has a reason to act more considerately, and saying one of the many things we can say...?" (Williams 1995, 39-40).

Before I explain why I find Williams' way of dealing with this hard case unsatisfactory, I want to summarize his argument. Since we might be tempted to say to the hard case that he had a reason to be nicer to his wife, or that he ought to have been nicer to her, and since such remarks seem to be connected with reasons, they must (in this case) be connected to external reasons. This is because the man had no appropriate element in his S. Williams says just what the internalist should say here, which is that the man really doesn't have a reason, and so our blaming him in that way is inappropriate. This solves the problem because, according to Williams, that really is the right result: he doesn't have a reason, and so we cannot ascribe one to him, but there are still a lot of other things we can say. So, rather than being disturbed at our inability to ascribe a reason to this person, we should wonder instead why the externalist wants to do this, and why we should think that is appropriate.

I don't think this analysis will work, because the kinds of things Williams thinks we can say to this man only make clear sense if we ascribe a reason to him as well. To see this, consider the sorts of things that, according to Williams, we can say to this man without ascribing a reason to him: we can say that he is nasty, inconsiderate, cruel, ungrateful, etc. And we can say that it would have been better if he had been nicer to his wife. But what is crucial here is that we can call him nasty and cruel for failing to do something he had no reason to do. He had no reason to be nice to his wife, but nonetheless, we can justifiably tell him that he is inconsiderate or selfish for failing to be nice to her. The moral judgments Williams claims we can make here all clearly appeal to terms of negative normative appraisal. "Nasty" and "inconsiderate" may also be descriptive of someone's behavior; certainly it isn't the case that just any action qualifies as nasty or inconsiderate. Grant-

\footnotetext{
${ }^{5}$ With these latter two expressions, however, we cannot mean that he had a reason to act otherwise, or that he ought to have done so. Expressions of this sort are perfectly legitimate as expressions of our moral views of the matter, but we cannot use them to ascribe a reason to him.
} 
Elizabeth A. Oljar

ing that such terms have descriptive content, they are not neutral with respect to someone's behavior. But where is the normative force of these terms supposed to come from? It seems very plausible to say that it comes from the fact that the man had a reason to be nicer to his wife, or that he ought to have been nicer to her. So, with respect to attributes such as nastiness or selfishness, we can say that "...the notion of a reason for action seems logically prior to the notion of a person possessing such an attribute..." (Haines 1988, 210). ${ }^{6}$ If this is correct, then our inability to intelligibly ascribe a reason to the husband deprives the characterization of his behavior as 'nasty' or 'cruel' of any normative force. The result is that we are left without resources for moral criticism, because the normative force of what Williams thinks we can say depends crucially on the normative force of what (he claims) we cannot say: namely, that he had a reason to be kind to his wife, or ought to have been nicer to her.

The same point applies to Williams' claim that the hard case is precisely the sort of person who we don't blame, but rather regard as "hopeless and dangerous," since his S does not contain any desire which would make an internal reason-statement true. However, I think it is at least unclear that blaming the hard case by ascribing a reason to him is inconsistent with regarding him as hopeless or dangerous. In this context, it is clear that "hopeless" and "dangerous" are terms of negative normative appraisal, as are terms like "nasty" or "selfish." But if a term such as "selfish" or "nasty" derives its normative force from the normative force of a reason, then it seems plausible to claim that the same is true of a term such as "hopeless" or "dangerous." In fact, it seems reasonable to regard the hard case as hopeless and dangerous precisely because he fails to grasp the objective (that is, motivation-independent) authority of certain reason-statements. If this is right, then it is externalism's commitment to the claim that the justificatory weight of reasons is independent of an agent's motives that provides a better account of this fact.

It might be objected that the normative force of such terms derives from the fact that the man has failed to meet our normative standards, or as Williams puts it, his "behaviour does not accord with what we think it should be" (Williams 1995, 40). And presumably, we can say something like this without saying that he had a reason to be nicer to his wife. Now, it's clear enough that we can say that his $\mathrm{S}$ is not like ours (or indeed like almost everyone else's), and that our motivational sets are such that we would have

\footnotetext{
${ }^{6}$ Scanlon makes a similar point about the logical relationship between character deficiencies such as nastiness and the concept of a reason for action; see Scanlon $1998,367$.
} 
a reason to be nicer to our spouses. But to point this out is simply to notice that there are descriptive differences between his motivational set and ours, and no such descriptive distinction conveys the normative force that is intended when we use a term like 'nasty.' One way to see this is to notice that our hypothetical husband could agree that his behavior doesn't accord with our normative standards without agreeing with our characterization of his behavior in these terms. Unless our standards of what a person's behavior "should be" themselves have some normative authority, then pointing out that his behavior does not accord with those standards has no more moral force than claims about eye color. ${ }^{7}$ In calling him nasty, we surely want to say something more than that he is not like us, though of course it's true that he's not. I can summarize the point I want to make here by answering the question that Williams posed, a question about what makes it appropriate to say the man had a reason, or what the ascription of a reason to him is supposed to add to all those things we can say. It's appropriate to say that he had a reason because that claim makes sense of our calling him inconsiderate, or selfish, or brutal. The normative force of these terms derives from the normative force of the reasons that are logically prior to their application. And given the state of his $\mathrm{S}$, the reason thus ascribed must be an external reason.

Although my discussion thus far has emphasized the logical relationship between terms of negative normative appraisal and reasons for action, it is worth pointing out in a more explicit way the deeper conflict of intuitions about reasons that both underlies this particular dispute, and in general divides internalists and externalists. Williams' straightforward concession that the husband has no reason to be nice to his wife (in virtue of the state of his $\mathrm{S}$ ), reflects the way in which internalism holds reason-statements "hostage" to the subjective psychological states of an agent. A slightly different (but helpful) way to put the point is that Williams' claim reflects the inter-

\footnotetext{
${ }^{7}$ This explains why an appeal to a non-cognitivist theory of normative language will not help here. The sort of remarks that Williams claims we can make (e.g., that the hard case is not behaving as we think he should) are cited approvingly by Simon Blackburn (Blackburn 1998, 265). Blackburn states that in a case of this sort, we appeal to our own moral standards in ascribing blame, and asks what else we should be doing. The problem is that unless the hard case has, prior to this situation, a reason to care about belonging to our moral community, or to care about being like us in the relevant sense, it is difficult to see why an appeal to our normative standards should carry any weight with him. It won't do here to simply assert that we are making a normative judgment of the hard case by appealing to our own standards, for this fails to answer the question about the source or ground of that normative force.
} 
Elizabeth A. Oljar

nalist's view that the authority or justificatory weight of reason-claims is relative to the psychological states of the agent. It is a deep discomfort with this idea that (at least in part) motivates externalism. Thus, if internalism is required in order to make sense of the idea that reason-claims are practical or action-guiding, as internalists typically claim, then we need to reconsider exactly what we mean by the practical or action-guiding function of both reason-claims in particular, and normative claims in general. The externalist does not deny that ethics (including claims about reasons) is practical or action-guiding; rather, she will argue that internalism is not the correct way of representing this feature of morality. ${ }^{8}$

\section{IS BLAME A PROBLEM FOR EXTERNALISM?}

In considering Williams' claim that blame is a problem for the externalist, it helps to keep in mind the two different ways this claim is supported. It is indirectly supported by the discussion of the previous section, since Williams believes that the externalist cannot explain the necessity of ascribing a reason to the unkind husband. This explanatory failure would itself show that the practice of blame is a problem for externalist accounts of reasons. I have argued, however, that the externalist can explain the necessity of ascribing a reason in such cases; indeed, ascribing such a reason seems required by Williams' own claims about the forms of moral criticism that are

\footnotetext{
${ }^{8}$ See Brink 1986 for a discussion of this point. The claim that internalism is committed to a form of relativism that we should reject is not new, but Brink's expression of this idea in terms of moral demands being held "hostage to people's actual desires" is a helpful way to put the point. As he says in the same paper, "[I]t is no vindication of the importance of moral demands if, in order to insure their motivational force, we must compromise the moral demands themselves" (Brink 1986, 29).

Brink's point applies most clearly to those versions of internalism (including Williams') that are the result of accepting a Humean belief-desire model of reasons, according to which the mere belief that something is the case has no intrinsic motivational force. Since reasons do have such force, its source must lie in the agent's desires (broadly construed). For Hume's views on these matters, see Hume 1978, esp. Book II, Part II, Section III and Book III, Part I, Section I.

As I indicated in note 4, however, there are both Humean and Kantian versions of internalism. In fact, Kantian versions of internalism (such as Darwall's) can be usefully understood as attempts to show that the key insight of internalism (that reasons necessarily have motivating force) can be preserved without adopting a belief-desire model of reasons. Indeed, Darwall argues for precisely this claim in Darwall 1983. While I think that even Kantian inspired versions of internalism are also subject to Brink's point here, or to some variation of it, the argument for this is rightly the topic of another paper.
} 
open to us. However, Williams argues that this is not the only problem that blame poses for an externalist; there is a further difficulty waiting in the philosophical wings. What is that problem supposed to be?

The problem is that if we insist on blaming the man who is not nice to his wife by saying that he ought to have been nicer to her, we won't be able to distinguish between that very hard (and very rare) case, and the more ordinary case where someone does have an appropriate element in his S. In the latter sort of case, our saying to a person that he ought to have $\varphi d$ functions as a way of making it true that he has an (internal) reason to $\varphi$. So, we have two different sorts of cases: the very hard case, and what we can call the "ordinary case." In both cases, the externalist wants to blame the person by saying that he had a reason to $\varphi$. But then what is the distinction between a case where saying this might have some effect (the ordinary case) and one where it won't (the hard case)? If there is a difference between the two cases, it can't be one that is revealed by saying "you ought to have been (or had reason to be) nicer to your wife," because the whole point for an externalist is that we say that in both cases. So, if these cases are different, as they clearly are, how is the externalist to explain the difference? As Williams puts this, "[E]xternalism is indeed external, and the image of blame that can be derived from its account of reasons, in failing to provide any way to engage with an agent's actual motivations, leaves us also without ethical resources. It gives us no way of understanding the difference between a blame that might hope to achieve recognition, and the blame that hopes by mere force to focus on the agent's reasons a judgment that represents in fact only a rejection... of what he has done" (Williams 1995, 44).

The first thing to notice here is Williams' assumption that if the externalist cannot differentiate the cases by ascribing a reason in one case but not the other, then there is no difference between them. The externalist can and should question this assumption. From the fact that the ascription of a reason is not what differentiates the two cases, it doesn't follow that there is no other way to differentiate between them. Thus, the question here is what those other ways might be. In considering this, it's worth noticing that blaming rarely (if ever) ends simply with a claim such as "you ought to have done $\varphi$." If it did, we really would be lacking in ethical resources. So, while Williams is right that we may say this in both the ordinary case and the hard one, the matter almost never ends there, nor need it. We can and do typically go on to say other things, and it is here that the differences will emerge.

To see how this might go, consider the hard case that Williams has provided, and a more ordinary case in which a man who is typically very nice to his wife inadvertently or unintentionally says something that hurts 
Elizabeth A. Oljar

her feelings very much. And let's suppose that from her reaction, he doesn't immediately realize he has hurt her; she is rather adept at hiding her feelings in such circumstances. Suppose further that someone else is present - her best friend, perhaps - and the friend does notice that the wife has been hurt. The friend says, "you know, you ought not to have said X. It really hurt her feelings." To speak to Williams' concern here, we have to suppose that the hard case said something similar to his wife, and we want to say to him exactly what we said to the ordinary case.

If this were the end of matters, and nothing more was said, then there would be no observable difference between the two cases. But that rarely ever is the end of matters, even in the hard case, for Williams tells us exactly the sort of response we can expect from him: "I really don't care. Don't you see? I simply do not care" (Williams 1995, 39). In the ordinary case, however, the man may express surprise, or say something like, "I had no idea that my saying X hurt her feelings." In the ordinary case, the friend would say something like, "just apologize and explain that it was unintentional," whereas faced with the responses of the hard case, it is (at the very least) less obvious what to say, or even whether anything should be said.

These seem to me like quite plausible "follow-up" remarks, though it's more difficult to be sure of this in the hard case. But from the fact that "you ought not have said X" is said to both, it does not follow that we have no resources for tailoring additional remarks to the specific case. What we know, or can reasonably assume, about the person in question, including things we know or assume about his $\mathrm{S}$ provides these resources. The externalist has to grant that we cannot tell the difference between the hard case and the ordinary one all and only on the basis of the "ought to have" claim, for these are the same. But no externalist need grant that this is the end of the matter, especially when dealing with the kind of complex moral practice that is involved here. The difference, the externalist should say, is in the details.

The point I'm making here can be strengthened by considering a distinction commonly made in moral philosophy between the rightness or wrongness of an action and the praiseworthiness or blameworthiness of the agent. From the fact that two actions are both judged to be right, it doesn't follow that the agents who performed them are equally praiseworthy. Mill's example of rescuing a drowning person remains particularly powerful for making this point: if rescuing the person maximizes utility, then I do the right thing in rescuing him, whether I am moved by alleviating the distress of others or the hope of a monetary reward (Mill 1957, 23-24). The application of this point to Williams' claims about externalism will perhaps be easier to see if we imagine two people in danger of drowning, and two other people who 
are each in a position to rescue one of the struggling swimmers. One rescuer, aware that the person he saves is quite wealthy, is moved by hopes of a reward, and perhaps a story about his "heroism" in the local paper. The other rescuer is moved to save his swimmer by his desire to alleviate suffering in the world when he can. The difference between these two cases does not lie in whether one is right and the other wrong, for rescuing is the right thing to do in both cases. ${ }^{9}$ Since we cannot differentiate these cases by saying that the act of rescuing was morally right in one case but not in another, does it follow that we cannot differentiate them? Clearly not. We're simply not looking for the difference in the right place: the difference is revealed by their motives; one agent deserves moral praise while the other does not. Analogously, does it follow from the fact that Williams' hard and ordinary cases are not distinguished by the ascription of reasons that there is no way to distinguish them? I have argued that it does not, especially in light of the complexity of the moral practice of blame. If Williams is right, then there is a neat, clean, purely theoretical distinction between the ordinary and the hard case: the former has a reason and the latter does not. If the externalist is right, then since both the ordinary and the hard cases have a reason, the distinction must be drawn differently: in the ordinary case, the agent both recognizes and is moved by a reason, while the hard case neither recognizes nor is moved by the reason. In any given situation, the determination of whether one is dealing with an ordinary or a hard case will depend on the particular circumstances, needs, interests, and motives of the individuals involved. And that sort of complexity is what we would expect to find in sophisticated moral practices such as blaming.

Williams might object at this point that all I've shown is that blame is effective in one case but not the other, a fact which he recognizes himself. But that doesn't explain why blame is effective in one case but not the other. The only way (or perhaps, the best way) to explain the difference in effectiveness is by appealing to the internalist claim that there is an internal reason in one case but not the other. In response, I would suggest that the difference in effectiveness is really all we need here; at least, it is unclear that a further explanation of that difference is philosophically necessary, since I strongly suspect that any such further explanation will depend on facts about an agent's psychological makeup. Moreover, the insistence on differentiating these cases in terms of the truth or falsity of the reasonstatement seems question-begging: why should we think that the difference between these two cases has to be understood in that way, unless we are

\footnotetext{
${ }^{9}$ This claim seems plausible whether one analyzes right action in utilitarian terms or not.
} 
Elizabeth A. Oljar

antecedently convinced of the truth of internalism? It doesn't seem as though either common sense moral thinking, or our actual practice of blaming requires this. In the absence of a further argument for the claim that these cases must be differentiated in terms of the presence or absence of an internal reason, the externalist account of the differences in these cases seems perfectly legitimate. ${ }^{10}$

Elizabeth A. Oljar

University of Detroit Mercy

Department of Philosophy

4001 W. McNichols Rd.

Detroit, MI 48219, USA

oljarea@udmercy.edu

\section{References}

Blackburn, Simon. 1998. Ruling Passions: A Theory of Practical Reasoning. Oxford: Clarendon Press.

Brink, David O. 1986. Externalist Moral Realism. The Southern Journal of Philosophy 24 (supplement): 23-41.

. 1989. Moral Realism and the Foundations of Ethics. Cambridge: Cambridge University Press.

Cohon, Rachel. 1986. Are External Reasons Impossible? Ethics 96 (April): 545-556.

- 1993. Internalism About Reasons for Action. Pacific Philosophical Quarterly 74 (December): 256-288.

Darwall, Stephen L. 1983. Impartial Reason. Ithaca: Cornell University Press.

Haines, Byron L. 1986. Internalism and Moral Training. The Journal of Value Inquiry 20: 63-69.

_ 1988. Meeting Philippa Foot's Challenge to Moral Philosophers. The Journal of Value Inquiry 22: 207-221.

Hooker, Brad. 1987. Williams' Argument Against External Reasons. Analysis 47 (January): 42-44.

Hume, David. 1978. A Treatise of Human Nature. $2^{\text {nd }}$ edition edited by L.A. Selby-Bigge and P.H. Nidditch. Oxford: Clarendon Press.

\footnotetext{
${ }^{10}$ My greatest debt is to Jean Roberts for initial discussion of these issues. I also wish to thank Audre Brokes, James Hardy, and an anonymous reviewer at The Southern Journal of Philosophy for helpful discussion of earlier drafts of this paper. I am also grateful to an anonymous reviewer at Disputatio for helpful comments on this version.
} 
Blame and the Metaphysics of Practical Reasons

Mill, John Stuart. 1957. Utilitarianism. Edited by Oskar Piest. New York: Macmillan.

Scanlon, T.M. 1998. What we Owe to Each Other. Cambridge, MA: Belknap Press.

Williams, Bernard. 1981. Internal and External Reasons. In Moral Luck. Cambridge: Cambridge University Press.

. 1995. Internal Reasons and the Obscurity of Blame. In Making Sense of Humanity and Other Philosophical Papers. Cambridge: Cambridge University Press. 